\title{
Deep-water renewal in Lake Issyk-Kul driven by differential cooling
}

\author{
Frank Peeters, ${ }^{1}$ David Finger, ${ }^{2}$ Markus Hofer, Matthias Brennwald, David M. Livingstone, and \\ Rolf Kipfer ${ }^{3}$
}

Environmental Isotopes Group, Department of Water Resources and Drinking Water, Swiss Federal Institute of Environmental Science and Technology (EAWAG), Überlandstrasse 133, CH-8600 Dübendorf, Switzerland

\begin{abstract}
During two field campaigns on Lake Issyk-Kul in March and August 2001, 179 high-resolution conductivitytemperature-depth profiles were measured, along with profiles of dissolved oxygen and light transmission. On the basis of this extensive data set, we investigated the large-scale vertical advective processes responsible for deepwater renewal in Lake Issyk-Kul. At some locations sampled in March, variable peak structures in the tracer profiles were observed that indicate horizontally localized intrusions. These intrusions have their origin in density plumes that propagate along the bottom of the channels in the eastern shelf region. The cold dense water at the bottom of the channels is most likely generated by differential cooling of the water in the shallow shelf regions during winter. During summer, vertical advective processes appear to be limited to the upper $200 \mathrm{~m}$, where upwelling in the open water leads to a doming structure. The August data support the results of earlier investigations that suggested that dynamic forcing by a basinwide gyre is responsible for the upwelling in the open water.
\end{abstract}

Lake Issyk-Kul, which is located at an altitude of 1,606 $\mathrm{m}$ in the Tien Chan mountains of northeast Kyrgyzstan, is one of the largest $\left(1740 \mathrm{~km}^{3}\right)$ and deepest $(668 \mathrm{~m})$ lakes in the world. It is a closed basin lake and is slightly saline, with $6 \mathrm{~g} \mathrm{~kg}^{-1}$ of dissolved ionic substances (Tsigelnaya 1995). Despite its depth, the lake has large, shallow shelf regions, predominantly in the east and west (Fig. 1a). Twenty-seven percent of the lake (by area) is shallower than 50 $\mathrm{m}$. During previous periods of low lake level, the area of the lake was therefore considerably less than it is now. The river valleys that were cut into the land surrounding the lake at this time were later submerged as the lake level rose and are now easily recognizable on the bathymetric map of Lake Issyk-Kul (Fig. 1a) as channels cut into what are now the shallow regions of the lake (Tsigelnaya 1995).

More than $50 \%$ of the water volume of the lake is located below $200 \mathrm{~m}$ depth. Hence, the exchange between surface and deep water is an important factor in determining the distribution of dissolved substances in the lake and must be taken into account in assessing the ecological impact of pollutants and nutrients possibly introduced by spills (associ-

\footnotetext{
${ }^{1}$ To whom correspondence should be addressed. Present address: University of Konstanz, Limnological Institute, Mainaustr. 225, D78457 Konstanz, Germany (Frank.Peeters@uni-konstanz.de).

${ }^{2}$ Present address: Department of Applied Aquatic Ecology, Lake Research Center, Swiss Federal Institute of Environmental Science and Technology, Kastanienbaum, Switzerland.

${ }^{3}$ Also affiliated with Isotope Geology, Department of Earth Sciences, Swiss Federal Institute of Science and Technology, Zurich, Switzerland.

\section{Acknowledgments}

We thank Prof. Jan Klerkx; our European, Russian, and Kyrgyz colleagues; and the crew of the Moltur for their excellent support and for the pleasant atmosphere that prevailed during the expeditions. Our research was made possible by funding from the Swiss Federal Office of Education and Science (contract 99.0720) within the framework of the European Union INCO/COPERNICUS Project Assessment and Prognosis of Environmental Changes in Lake Issyk-Kul (Kyrgyzstan) (contract ICA2-CT-2000-10003).
}

ated, e.g., with the mining activities in the lake's catchment) or by the continuous release of nutrients from sewage plants.

On the basis of ${ }^{3} \mathrm{H}$ concentrations measured in samples collected in 1976 (Romanov et al. 1989) and on dissolved oxygen and conductivity-temperature-depth (CTD) data, Kipfer and Peeters (2002) suggested that deep-water renewal in Lake Issyk-Kul is rapid and that the residence time of the deep water of the lake can be expected to be $<13$ yr. Using new data on the transient tracers ${ }^{3} \mathrm{H},{ }^{3} \mathrm{He}$, sulfur hexafluoride $\left(\mathrm{SF}_{6}\right)$, and chlorofluorocarbons (e.g., CFC-12), deep-water residence times were estimated to be $<10 \mathrm{yr}$ (Hofer et al. 2002; Vollmer et al. 2002a). However, the transient tracer data do not allow the identification of the processes responsible for deep-water renewal. An understanding of these processes is a prerequisite for predicting the influence of environmental and climatic change on the mixing processes themselves and, hence, on the distribution of dissolved substances in the lake.

Dissolved substances can be transported from the surface to the deep water by vertical turbulent diffusion and by advective processes. Vertical turbulent diffusion always causes heat to flow from high to low temperatures and hence leads to a gradual, continuous warming of cold, deep-water regions. In Lake Issyk-Kul, deep-water temperatures typically decrease with increasing depth during all seasons, reaching minimum values at greatest depth, which indicates that advective processes transporting cold surface water to the deep-water region must be sufficiently important to compensate for the heat flux due to turbulent diffusion (Kipfer and Peeters 2002).

In the world's largest and deepest water bodies, several processes have been identified that lead to advective deepwater renewal: river inflow, for example, in Lake Baikal (Hohmann et al. 1997) and possibly in Lake Tanganyika (Kipfer et al. 2000); interbasin exchange, for example, in Lake Baikal (Peeters et al. 1996; Hohmann et al. 1997) and the Caspian Sea (Peeters et al. 2000); thermal-bar mixing, for example, in the Laurentian Great Lakes (Rodgers 1965), Lake Baikal (Shimaraev et al. 1993; Peeters et al. 1996; 


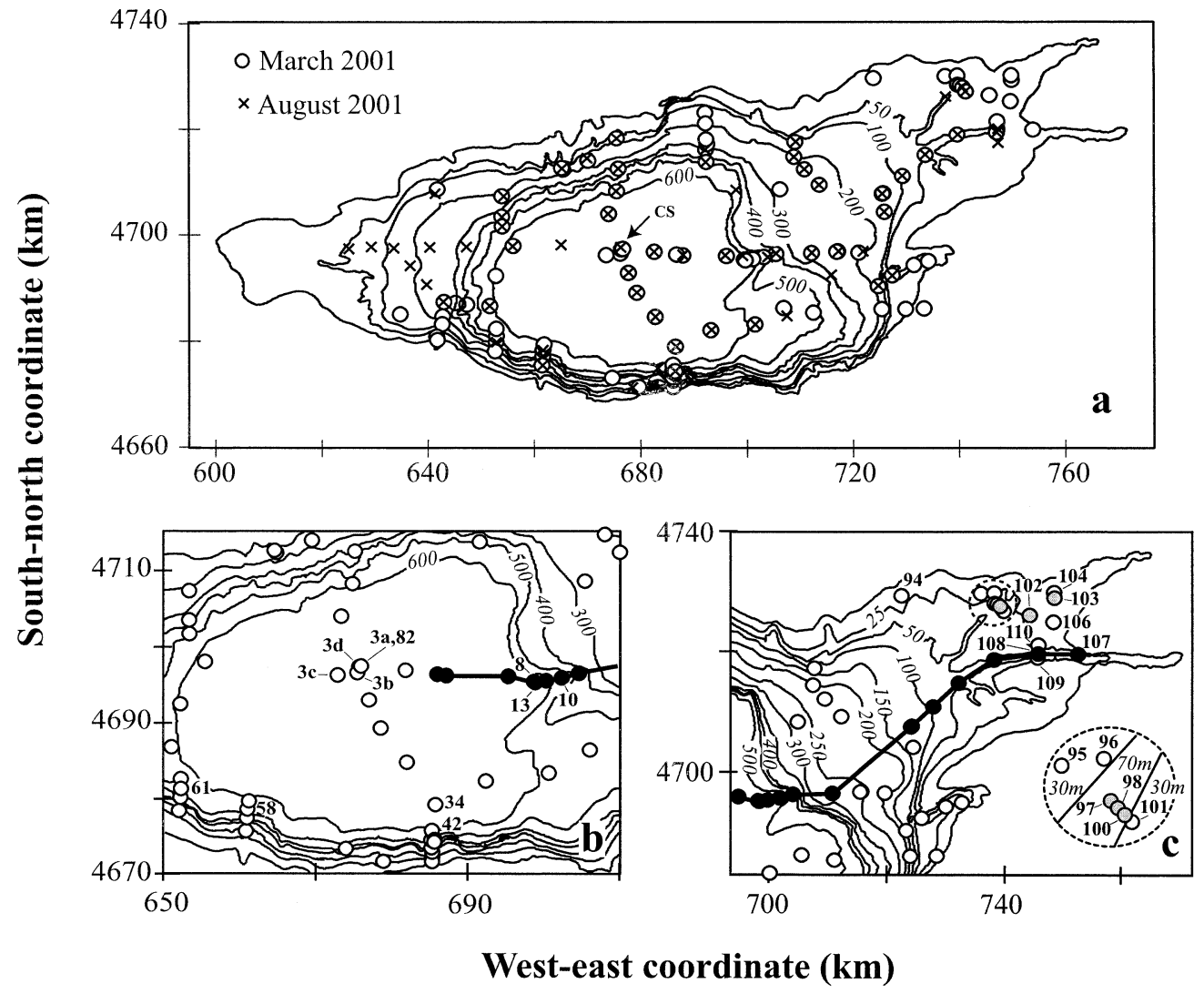

Fig. 1. Map of stations at which high-resolution CTD data were collected during the 2001 IssykKul field campaigns (UTM coordinates). (a) Locations of CTD stations sampled in March and August 2001. "CS" indicates the central stations of the March expedition (Sta. 3) and the August expedition (Sta. 203). More detailed information on the stations occupied in March is provided for the central and eastern regions in panels b and c, respectively. (b) Station numbers are provided for stations with intrusions and for Sta. 82. (c) Numbered stations with gray and solid circles were located at channels in the shelf region, whereas numbered stations with open circles were located on the shelf shoulders (see Fig. 9). Solid circles connected by a solid line in panels b and c mark the stations of the Karakol transect (Fig. 7) from the central basin toward the mouth of the Karakol River.

Hohmann 1997; Hohmann et al. 1997), and Lake Ladoga (Malm et al. 1994); and transport due to thermobaric instabilities, for example, in Lake Baikal (Weiss et al. 1991; Walker and Watts 1995) and possibly in Crater Lake (McManus et al. 1992; Crawford and Collier 1997). All of these processes have been shown to contribute to deep-water renewal, although advective transport to the lake bottom could not be demonstrated in all cases.

In Lake Issyk-Kul, however, none of these processes is likely to be responsible for significant deep-water renewal. Because the salinity of Lake Issyk-Kul water is $\sim 6 \mathrm{~g} \mathrm{~kg}^{-1}$, the density of inflowing fresh river water is unlikely to be sufficient to drive density plumes to great depths. Interbasin exchange is not applicable (because Lake Issyk-Kul has only one basin). Thermal-bar mixing requires a horizontal interface where water temperature changes from above to below the temperature of maximum density $\left(T_{\mathrm{md}}\right)$, thus leading to cabbeling and the downward movement of water with temperature $T_{\mathrm{md}}$. However, in Lake Issyk-Kul, temperatures in the open-water region and at great depths always signifi- cantly exceed $T_{\text {md }}$, which is $\sim 2.6^{\circ} \mathrm{C}$ at the lake surface (Kipfer and Peeters 2002) and decreases with increasing depth. Deep-water renewal by thermobaric instabilities requires that deep-water temperatures be $<T_{\text {md }}$ at shallower depths, which is also not the case in Lake Issyk-Kul.

In the present study, we show the results from a large data set of high-resolution CTD profiles collected in Lake IssykKul with the aim of identifying the main processes responsible for deep-water ventilation. Results indicate the importance of differential cooling in this regard-a process whereby heat loss from the lake surface leads to horizontal temperature differences between deep-water areas of the lake and shallower shelf regions, resulting in the generation of density plumes that propagate along submerged river channels.

\section{Field data and calibration}

During two expeditions to Lake Issyk-Kul, one conducted in March 2001 and the other in August 2001, 179 CTD 
Table 1. Empirical coefficients of Eq. 1 for Issyk-Kul water (Finger 2002). Application of the coefficients in Eq. 1 assumes that $T$ is given in ${ }^{\circ} \mathrm{C}, p$ in dbar, and $C$ in $\mathrm{mS} \mathrm{cm}{ }^{-1}$. Resulting values of $S$ are in $\mathrm{g} \mathrm{kg}^{-1}$.

\begin{tabular}{lllll}
\hline \hline$a_{0}=-3.3688 \times 10^{-1}$ & $b_{0}=4.5867 \times 10^{-1}$ & $c_{0}=6.766097 \times 10^{-1}$ & $d_{1}=-3.516 \times 10^{-1}$ & $e_{1}=1.777 \times 10^{-5}$ \\
$a_{1}=1.2445$ & $b_{1}=-3.8378$ & $c_{1}=2.005640 \times 10^{-2}$ & $d_{2}=-4.693 \times 10^{-3}$ & $e_{2}=-1.967 \times 10^{-11}$ \\
$a_{2}=2.7876 \times 10^{1}$ & $b_{2}=9.3237$ & $c_{2}=1.104355 \times 10^{-4}$ & $d_{3}=6.188 \times 10^{-1}$ & $e_{3}=0$ \\
$a_{3}=2.1282 \times 10^{1}$ & $b_{3}=-3.8821$ & $c_{3}=-6.311915 \times 10^{-7}$ & $d_{4}=2.889$ & \\
$a_{4}=-1.6378$ & $b_{4}=-5.1411$ & $c_{4}=1.003100 \times 10^{-9}$ & & \\
$a_{5}=6.0350$ & $b_{5}=-4.1955$ & $k=5.7524 \times 10^{-3}$ & & \\
\hline
\end{tabular}

profiles were collected at numerous stations (Fig. 1) using an SBE-9 probe (Seabird Electronics). This probe provides a resolution of $0.0003^{\circ} \mathrm{C}$ for temperature $T, 0.01 \mu \mathrm{S} \mathrm{cm}-1$ for conductivity $C, 0.025 \mathrm{dbar}$ for pressure $p$, and $0.01 \mathrm{mg}$ $\mathrm{L}^{-1}$ for dissolved oxygen $\mathrm{O}_{2}$. According to Seabird Electronics, the drift of the conductivity sensor is significantly $<0.0003 \mathrm{~S} \mathrm{~m}^{-1}$ month $^{-1}$. The CTD probe was additionally equipped with a transmissometer (Chelsea Instruments) that provided a resolution of $0.1 \%$ for light transmission $L T$ at a path length of $25 \mathrm{~cm}$. The probe measures at a sampling frequency of $24 \mathrm{~Hz}$. In most cases, these measurements were averaged to obtain a sampling frequency of $6 \mathrm{~Hz}$, which was sufficient to provide more than five data points per meter of depth.

Salinity $S$ was calculated from $C, T$, and $p$ using the functional form of the UNESCO equations commonly used in oceanography to calculate $S$ from the measurement of the conductivity ratio $R$ (Fofonoff and Millard 1983):

$$
\begin{aligned}
S & =a_{0}+a_{1} R_{t}^{1 / 2}+a_{2} R_{t}+a_{3} R_{t}^{3 / 2}+a_{4} R_{t}^{2}+a_{5} R_{t}^{5 / 2}+\Delta S \\
R_{t} & =\frac{R}{\left(R_{p} \times r_{t}\right)} \\
R_{p} & =1+\frac{p\left(e_{1}+e_{2} p+e_{3} p^{2}\right)}{1+d_{1} T+d_{2} T^{2}+\left(d_{3}+d_{4} T\right) R} \\
r_{t}= & c_{0}+c_{1} T+c_{2} T^{2}+c_{3} T^{3}+c_{4} T^{4} \\
\Delta S= & \frac{(T-15)}{1+k(T-15)}\left(b_{0}+b_{1} R_{t}^{1 / 2}+b_{2} R_{t}+b_{3} R_{t}^{3 / 2}\right. \\
& \left.\quad+b_{4} R_{t}^{2}+b_{5} R_{t}^{5 / 2}\right)
\end{aligned}
$$

with

$$
R=\frac{C(S, T, p)}{C_{\mathrm{ref}}}
$$

where $R$ is the ratio of the measured conductivity to a reference conductivity $C_{\text {ref }}=42.9140 \mathrm{mS} \mathrm{cm}^{-1}$, which is the conductivity of $32.4356 \mathrm{~g} \mathrm{KCl}$ at $15^{\circ} \mathrm{C}$ and 1 atm (Culkin and Smith 1980). Equation 1f presupposes that the probe's sensor provides the correct absolute conductivity.

The application of Eq. 1 assumes that conductivity varies only because of changes in total ion concentration, $T$, and $p$ and that the relative ionic composition is the same everywhere in the lake. Because the ionic composition of Lake Issyk-Kul water differs from that of seawater, the empirical values of the coefficients of Eq. 1 were modified on the basis of several calibration experiments (Finger 2002, described below). The coefficients determined and used for calibration are given in Table 1.
Calibration experiments were performed to determine the dependence of $C$ on the total ion concentration, on $T$, and on $p$ (Finger 2002). Measuring always the same water by short-circuiting the pumping system of the SBE-9, the dependence of $C$ on $T$ at a given $S$ was determined in the laboratory by varying $T$ while keeping $p$ fixed. The laboratory experiments were performed using water from Lake Issyk-Kul diluted with different amounts of deionized water to $100 \%, 95 \%, 90 \%$, and $85 \%$ Issyk-Kul water. The absolute salinity of Issyk-Kul water was assumed to be $6 \mathrm{~g} \mathrm{~kg}^{-1}$. Hence, in each of the laboratory calibration runs, $S$ was known and $C, T$, and $p$ were measured. On the basis of these calibration data, the coefficients $a_{i}, b_{i}, c_{i}$, and $k$ of Eq. 1 were adjusted to minimize the least-squares deviation between the salinity obtained using Eq. 1 and the true salinity of the water used in the calibration runs.

The pressure dependence of $C$ was determined by shortcircuiting the pumping system of the SBE-9 in the field. Pressure was varied by rapidly raising the probe from the lowest depths of the lake ( $\sim 600 \mathrm{dbar})$. Two such calibration experiments were performed in March and two in August. Only the pressure range between 200 and 600 dbar was considered for the calibration of the coefficients $d_{i}$ and $e_{i}$, to avoid any influence of temperature variations of the water enclosed in the pumping system caused by heat diffusion in the warm upper water layers. Because the absolute salinities are not known in these experiments, the parameters $d_{i}$ and $e_{i}$ were adjusted to minimize the mean squared deviation between the salinity calculated using Eq. 1 and the mean of the calculated salinities in the corresponding experiment. This procedure makes use of the fact that the salinity is constant in each of the four pressure calibration experiments.

Recently, Vollmer et al. (2002b) adopted the calibration procedure and methods of Finger (2002), providing an additional set of coefficients for the dependence of conductivity on temperature. We used the original coefficients determined by Finger (2002) because they were obtained with the same CTD probe used in our field experiments.

All salinities calculated for the March expedition were lower than those calculated for the August expedition. Because water levels rose between March and August 2001 by $\sim 15 \mathrm{~cm}$ (Institute of Water Problems and Water Power of Kyrgyszstan pers. comm.), which is typical for Lake IssykKul during this time period (Tsigelnaya 1995), the difference in salinities is most likely the result of a shift in the absolute sensitivity of the conductivity sensor. To avoid misinterpretation due to unreasonable differences in the absolute salinities, the August salinities $S_{A}$ were scaled to $S_{A}=0.9987 \mathrm{~S}$, such that the mean salinity in the median salinity profiles of 


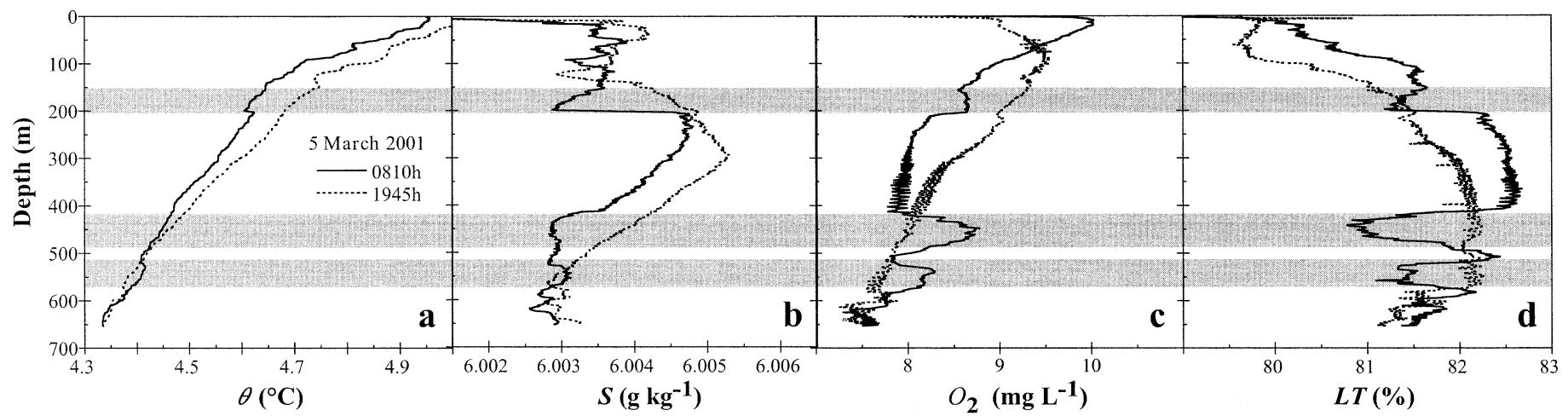

Fig. 2. Profiles of potential temperature $(\theta)$, salinity $(S)$, dissolved oxygen $\left(\mathrm{O}_{2}\right)$, and light transmission $(L T)$ in the deepest region of Lake Issyk-Kul measured on 5 March 2001 at 0810 h (solid lines, Sta. 3a) and 1945 h (dashed lines, Sta. 3d). The horizontal gray bars indicate the depths of specific features discussed in the text.

the March expedition agreed with that of the median salinity profile of the August expedition. The median of the salinity profiles from each expedition was determined by calculating the mean salinity between 300 and $500 \mathrm{~m}$ and then ranking the resulting salinities for each expedition. This procedure implicitly assumes that salinities between 300 and $500 \mathrm{~m}$ depth did not change significantly from March to August 2001. Further details on the salinity calibration experiments are given by Finger (2002).

Note that, in the present study, salinity, dissolved oxygen, and light transmission were primarily used as tracers to identify intrusions, and, therefore, absolute quantitative calibrations of these variables were not required. Although the absolute value of salinity is known only to within $\sim 5 \%$, the relative variation of $S$ within a profile can be determined from Eq. 1 with an error $<0.001 \mathrm{~g} \mathrm{~kg}^{-1} \mathrm{~K}^{-1}$ at fixed pressure and $<0.0003 \mathrm{~g} \mathrm{~kg}^{-1}$ per $100 \mathrm{~m}$ depth at fixed temperature between $4^{\circ} \mathrm{C}$ and $6^{\circ} \mathrm{C}$ (Finger 2002). Dissolved oxygen and light transmission were not calibrated to represent absolute values of dissolved oxygen and the amount of suspended particles, respectively. However, the oxygen sensor was new and had been calibrated immediately prior to the March expedition. The values for $\mathrm{O}_{2}$ provided by the oxygen sensor agreed well with $\mathrm{O}_{2}$ values obtained from Winkler titration performed on water samples collected at corresponding depths. Unfortunately, the oxygen sensor froze during the last third of the March expedition, for which no $\mathrm{O}_{2}$ data are therefore available. During the August campaign, the data from the oxygen sensor were shifted slightly with respect to the few Winkler data available. We therefore use the $\mathrm{O}_{2}$ data from August only in a relative sense to identify peak structures. The transmissometer data were interpreted in a simplified manner: a decrease in light transmission was interpreted merely to indicate an increase in the concentration of suspended particles.

The density function for Lake Issyk-Kul water $\rho_{\text {Issyk }}(T, S, p)$ was obtained according to the procedure outlined by Peeters et al. (2000) by modifying the equation of state for seawater $\rho_{\text {sea }}$ (UNESCO et al. 1981) to account for the ionic composition of Lake Issyk-Kul water as follows:

$$
\begin{aligned}
\rho_{\text {Issyk }}(T, S, p)= & \rho_{\text {sea }}(T, 0, p) \\
& +f\left[\rho_{\text {sea }}(T, S, p)-\rho_{\text {sea }}(T, 0, p)\right]
\end{aligned}
$$

where $\rho_{\text {sea }}(T, S, p)$ is the density function of seawater. The scaling factor $f=1.0764$ was determined using the ionic composition of Issyk-Kul water given by Tsigelnaya (1995). Using this equation of state and assuming $S=6 \mathrm{~g} \mathrm{~kg}^{-1}$, the temperature of maximum density $T_{\mathrm{md}}$ at the surface of Lake Issyk-Kul is $T_{\mathrm{md}}=2.6^{\circ} \mathrm{C}$ (Hofer et al. 2002; Kipfer and Peeters 2002).

\section{Results and discussion}

Spring mixing processes-Vertical distribution of $\theta, S, \mathrm{O}_{2}$, and $L T$ : In Fig. 2, profiles of potential temperature $\theta, S, \mathrm{O}_{2}$, and $L T$ measured on 5 March 2001 at $0810 \mathrm{~h}$ at the deepest station (Sta. 3a, solid lines) are compared with profiles measured at the same location on the same day at $1945 \mathrm{~h}$ (Sta. $3 \mathrm{~d}$, dotted lines). In Lake Issyk-Kul, the potential temperature $\theta$ varies only slightly from the measured in situ temperature $T$, and even at the greatest depth the difference is only $\sim 0.02^{\circ} \mathrm{C}$. Thus, although for the sake of theoretical correctness the potential temperature $\theta$ is used in the present study, the error involved in using the measured in situ temperature $T$ in Issyk-Kul would in fact be slight. The potential temperature generally decreases with increasing depth. This is typical for all $\theta$ profiles from the March expedition, although slight deviations from this decreasing trend can be observed in the profile from Sta. 3a, especially in the upper $200 \mathrm{~m}$ but also in deeper regions just below $500 \mathrm{~m}$ depth (Fig. 2). In the deep water of the lake (>600 $\mathrm{m}$ depth), $\theta$ ranged between $4.33^{\circ} \mathrm{C}$ and $4.40^{\circ} \mathrm{C}$, which are the highest values ever observed in the deep water of Lake Issyk-Kul. $\theta$ near the surface ranged between $4^{\circ} \mathrm{C}$ and $6^{\circ} \mathrm{C}$ in almost all profiles from the March expedition. The difference between the two $\theta$ profiles in Fig. 2 indicates that, at a given station, $\theta$ can vary significantly within $\sim 12 \mathrm{~h}$.

In March, $S$ typically varied by $<0.1 \%$ within a profile. At intermediate depths between 200 and $500 \mathrm{~m}, S$ appeared to be higher than near the surface and in the deep water. In the profile from Sta. 3a at $\sim 200 \mathrm{~m}$ depth, $S$ could be seen 
to change by $>0.001 \mathrm{~g} \mathrm{~kg}^{-1}$ (from the value prevailing in the region above $200 \mathrm{~m}$ to that prevailing at intermediate depth) within only a few meters (Fig. 2b).

Dissolved oxygen concentrations generally decrease with increasing depth. Near the surface, $\mathrm{O}_{2}$ is close to atmospheric saturation $\left(9.9 \mathrm{mg} \mathrm{L}^{-1}\right.$ at $T=5^{\circ} \mathrm{C}, S=6 \mathrm{~g} \mathrm{~kg}^{-1}$, and $p=$ $0.813 \mathrm{~atm})$ but even at the greatest depths, oxygen concentrations are still $\sim 75 \%$ of the saturation concentration at ambient temperature and surface pressure. These absolute values were confirmed by Winkler titration. They agree very well with the chemically determined concentrations measured by Vollmer et al. (2002a) in water samples collected in September 2000. The $\mathrm{O}_{2}$ profiles have features that are especially distinct in the profile from Sta. $3 \mathrm{a}$ at $\sim 200, \sim 450$, and $\sim 550 \mathrm{~m}$ depth (Fig. $2 \mathrm{c}$, horizontal gray bars). The profile measured at the same location $<12$ h later does not show the same features.

Light transmission generally increases with depth down to $500 \mathrm{~m}$ and then decreases slightly down to maximum depth (Fig. 2d). However, very distinct regions in which $L T$ decreases strongly make it difficult to determine a definite trend of $L T$ with depth. The specific regions of strong decrease in $L T$ in the profile from Sta. 3a coincide with those in which $\mathrm{O}_{2}$ increases. Interpreting the features in the tracer distributions between 150 and $200 \mathrm{~m}$ as peaks, the decrease in $L T$ at $\sim 180 \mathrm{~m}$ coincides with an increase in $\mathrm{O}_{2}$, and decreases in $\rho$ and $S$ (Fig. 2, upper horizontal gray bar).

The different peaks in the tracer profiles cannot be explained if deep-water renewal in Lake Issyk-Kul is thought of as a local vertical diffusive process, because such a process would smooth out concentration gradients rather than generating peak structures. At Sta. 3a, the peaks in the profiles of the different tracers are at the same depths (Fig. 2, horizontal gray bars). Hence, the specific features at $\sim 180$, $\sim 450$, and $\sim 550 \mathrm{~m}$ depth indicate intrusions of water masses having characteristic properties different from those of the typical background profile in the deep-water region.

Origin of the intrusions: Identification of the origin of these intrusions became one of the main objectives of the field campaign in March. The increased oxygen levels of the intruding water suggest that the intrusions originate from the upper regions of the water column-that is, from above $\sim 200 \mathrm{~m}$ depth. This would also be consistent with the light transmission and salinity data. Because biodegradation leads to oxygen depletion, the intrusions are most likely recent features. This hypothesis is supported by the sharp gradients in the tracer concentrations at the upper and lower bounds of the intrusions, which would have been smoothed out by vertical turbulent diffusion if the intrusions had been older than a few months. Data on the transient tracers ${ }^{3} \mathrm{H},{ }^{3} \mathrm{He}$, and $\mathrm{SF}_{6}$ measured at Sta. 3 in 2001 (Hofer et al. 2002) suggest a decrease in apparent water age at $\sim 500 \mathrm{~m}$ depth. This observation is consistent with the interpretation that the intrusions are recent features containing water from upper regions of the water column.

Measurements made at Sta. 3 on 5 March 2001 show that specific features present in the profiles of $\theta, S, \mathrm{O}_{2}$, and $L T$ at any one point in the lake can change dramatically within as little as $1 \mathrm{~d}$ (Fig. 3a-d). The vertical extent of the features in the profiles is much too large and the changes in the profiles much too rapid for vertical mixing to have been responsible for the changes observed. The transient character of the intrusions suggests, rather, that the signals in the tracer concentrations are horizontally localized features that are being transported past the sampling site by large-scale horizontal advection. Drift-buoy measurements conducted during the March expedition indicated the presence of currents with horizontal velocities on the order of $0.5 \mathrm{~m} \mathrm{~s}^{-1}$ down to at least $350 \mathrm{~m}$ depth (V. Podsetchine pers. comm.). Tracer profiles measured at essentially the same location $9 \mathrm{~d}$ later are shown in Fig. 3e (Sta. 82). No peaks are visible any more, but, in the deep water, $\theta$ shifted to lower and $S$ to higher values. However, the intrusions observed at Sta. 3 were not the result of a unique event, because intrusions could be observed in several regions of the lake. Peak structures in the deep water similar to those at the central Sta. 3 were observed during the March expedition in the eastern part of the deep basin at Sta. 8 (Kipfer and Peeters 2002), 10 , and 13 and in the southern part of the deep basin at Sta. 34, 42, 58, and 61 (see Fig. 1 b for station locations).

As indicated above, the existence of the intrusions suggests that water sinks from above $200 \mathrm{~m}$ down to the deep hypolimnion. However, because the intrusions in the deep hypolimnion have about the same potential temperature as the ambient water and $\theta$ in the open water decreases with increasing depth, it follows that, at its initial depth above $200 \mathrm{~m}$, the water responsible for generating the intrusions must have been colder than the open water at the center of the lake.

Almost everywhere in the water column, the quasi density $\rho_{\text {qua }}(T, S, p(z))$ increases with depth $z$ (Fig. 4a). The change in $\rho_{\text {qua }}$ with $z$ is proportional to the squared Brunt-Väisälä frequency $N^{2}$ (Peeters et al. 1996):

$$
\frac{d \rho_{\text {qua }}}{d z}=\frac{\rho_{\text {Issyk }}}{g} \times N^{2}(z)
$$

where the vertical coordinate $z$ is positive downward, and $g$ is the acceleration of gravity. $\rho_{\text {qua }}$ is more suitable than $N^{2}$ for investigating the local stability of the water column because it does not require the choice of a particular depth interval for differentiation. At locations where $\rho_{\text {qua }}$ increases with depth, the water column is stably stratified. This is the case at almost all depths in the profile shown in Fig. 4a. Only in very few sections of the profile does $\rho_{\text {qua }}$ decrease with increasing depth, which thus suggests that the water column is unstable at these depths (e.g., between 515 and 530 m; Fig. 4b).

Note, however, that the calculation of $\rho_{\text {qua }}$ does not include the effect of suspended particles on density. Within the intrusions (e.g., between 510 and $580 \mathrm{~m}$ ), $L T$ is typically reduced, which indicates an increased amount of suspended particles that would increase water density. Because the density differences are very slight, the water column at the depth of the intrusions might well be stabilized by the gradients in suspended solids, although $\rho_{\text {qua }}$ indicates marginally unstable conditions.

In the depth range between 450 and $550 \mathrm{~m}$ covered by Fig. $4 \mathrm{~b}$, salinity was, on average, $6.003 \mathrm{~g} \mathrm{~kg}^{-1}$. The change 

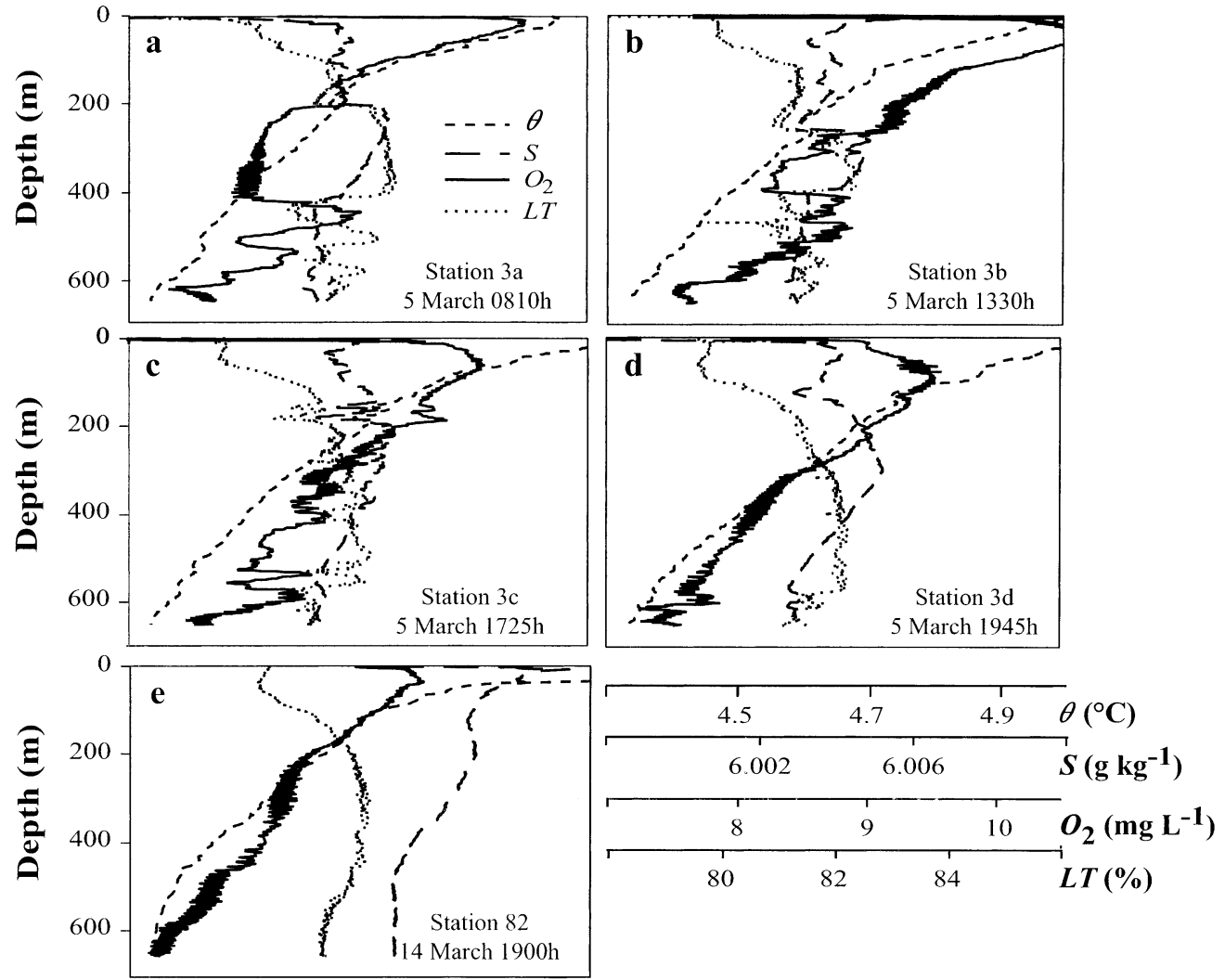

Fig. 3. Profiles illustrating the transient character of the intrusions observed in the deepest region of Lake Issyk-Kul. Profiles of $\theta, S, \mathrm{O}_{2}$ and $L T$ were measured on 5 March at $0810 \mathrm{~h}$ (a), $1330 \mathrm{~h}$ (b), $1725 \mathrm{~h}$ (c), $1945 \mathrm{~h}$ (d), and 9 d later on 14 March at $1900 \mathrm{~h}$ (e). See Fig. 1b for the locations of Sta. 3a-d and 82 .
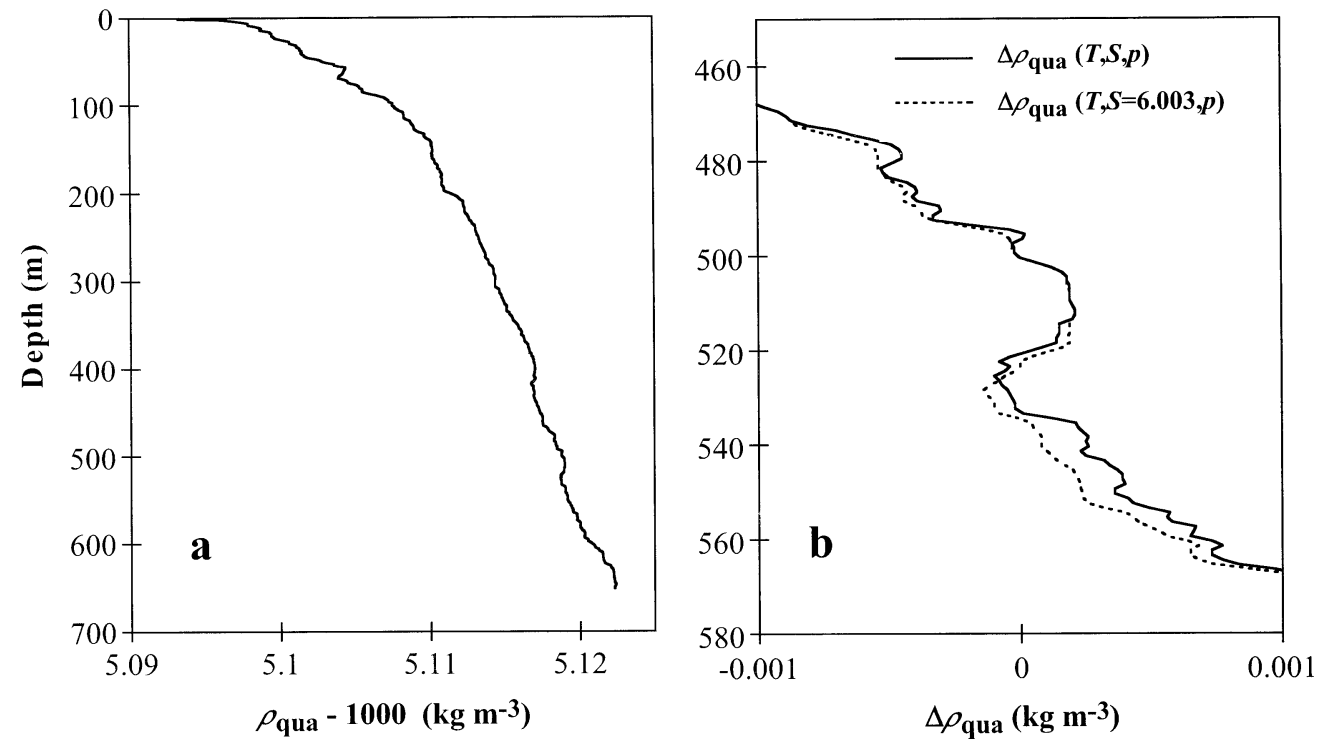

Fig. 4. Density stratification at Sta. 3a. (a) In most parts of the profile, $\rho_{\text {qua }}$ increases with increasing depth, indicating stable stratification. Only at $\sim 60,415$, and $520 \mathrm{~m}$ depth does the profile seem unstable. (b) $\Delta \rho_{\text {qua }}(T, S, p) \equiv \rho_{\text {qua }}[T, S, p(z)]-\rho_{\text {qua }}[T, S, p(z=500 \mathrm{~m})]$ (solid line) decreases from 512 to $526 \mathrm{~m}$. The close agreement between $\Delta \rho_{\text {qua }}(T, S, p)$ (solid line) and $\Delta \rho_{\text {qua }}\left(T, S=6.003 \mathrm{~g} \mathrm{~kg}^{-1}, p\right)$ (dashed line) indicates that salinity gradients have no significant effect on the density stratification. 

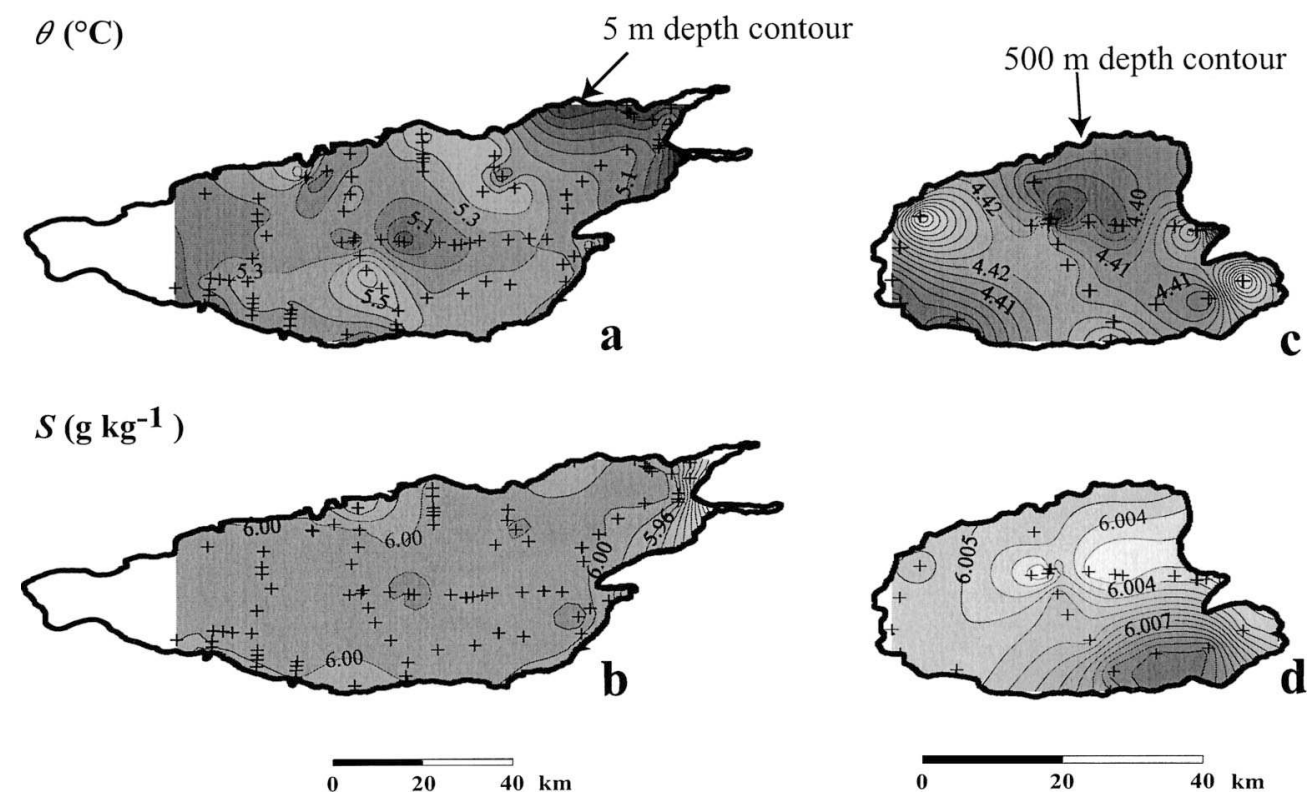

Fig. 5. Horizontal distribution of potential temperature $\theta$ (a and c) and salinity $S$ (b and d) in March 2001 at $5 \mathrm{~m}$ (a and b) and $500 \mathrm{~m}$ (c and d) depths. The symbols (+) indicate the locations of the sampling points.

with $\quad$ depth $\quad$ of $\quad \Delta \rho_{\text {qua }}(T, S, p) \equiv \rho_{\text {qua }}[T, S, p(z)] \quad-$ $\rho_{\text {qua }}[T, S, p(z=500 \mathrm{~m})]$ and of $\Delta \rho_{\text {qua }}\left(T, S=6.003 \mathrm{~g} \mathrm{~kg}^{-1}, p\right)$ is essentially the same (Fig. $4 \mathrm{~b}$ ). This demonstrates that the decrease in $\rho_{\text {qua }}$ in the peak at $\sim 530 \mathrm{~m}$ depth is predominantly determined by temperature effects. The influence of salinity on the stability is negligible, because salinity variations are small and the temperature at all depths is significantly greater than $T_{m d}$. Hence, the processes causing oxygen-rich water to advect as density plumes from shallower regions down to the greatest depths of the lake must be driven by horizontal temperature differences at shallower depths. Salinity differences most likely do not play a significant role in driving the deep-water mixing process, in particular because salinity within the intrusions can be lower than that of the ambient water. However, the salinity levels within the intrusions can serve as a tracer to identify the origin of the intruding water.

The horizontal distribution of near-surface temperatures indicates that the central region of the lake is generally warmer than the shallow eastern region (Fig. 5a). Near the surface, the salinity decreases significantly from the central part of the lake toward the east (Fig. 5b). The lake's two main inflows introduce fresh water into the eastern region of the lake, where it mixes with the lake water. At $500 \mathrm{~m}$ depth, $\theta$ varies by $\sim 0.1^{\circ} \mathrm{C}$ (Fig. 5c) without a clear spatial pattern, whereas $S$ undergoes a marked decrease along the central line of the lake from Sta. 3 eastward (Fig. 5d). Although the isoplots at $500 \mathrm{~m}$ are based on a rather limited data set, the distribution of $S$ suggests that water with comparatively low salinity is intruding from the eastern region of the lake.

During the March expedition, the coldest water was found in the shallow northeastern region of the lake (Fig. 5a). With one exception (Sta. 107), this was at the bottom of the above-mentioned submerged channels (Sta. 97, 98, 100, 102,
103, 107, and 108; Fig. 6a; see Fig. 1c for station locations). The density differences between water parcels moved isentropically to the same depth can be estimated in Lake IssykKul by using the concept of potential density. Potential density $\rho_{\text {pot }}$ is defined as the density that the water parcel at a given depth $z$ would have if transported isentropically to a reference level $z^{\prime}$ (e.g., the lake surface):

$$
\rho_{\mathrm{pot}}\left(z, z^{\prime}=0\right)=\rho_{\text {Issyk }}\left\{\theta\left(z, z^{\prime}=0\right), S(z), p=0\right\}
$$

where $\rho_{\text {Issyk }}$ is given by Eq. 2 . The potential density of the water at the bottom of many of the channels in the eastern basin exceeds that of the deep water at $\sim 600 \mathrm{~m}$ depth (Fig. $6 \mathrm{~b}$ ), which suggests that deep-water renewal is probably driven by density differences along these channels. Profiles of $\theta, S, L T$, and $\rho_{\text {pot }}$ at stations along the Karakol transect (Fig. 7; see Fig. 1 for station locations) support this hypothesis. The sampling stations included in the transect are along a deep canyon beginning at the mouth of the Karakol River and extending toward the deep central part of Lake Issyk-Kul (Fig. 1b,c; solid circles connected by a solid line). Compared with the open water at the same depth, the nearbottom region in the channel is characterized by low $\theta$, low $S$, high $L T$, and high $\rho_{\text {por }}$. The distribution of $\rho_{\text {pot }}$ is essentially determined by the $\theta$ distribution as discussed above. The high $\rho_{\text {pot }}$ near the bottom of the channel (Fig. 7d) indicates a density plume that propagates from the very east to the center of the lake along the bottom of the sunken riverbed. Unfortunately, the oxygen sensor failed during the third part of the expedition. However, the bottom water in other channels (e.g., at Sta. 98 and 103; see Fig. 1c) was saturated with oxygen, which suggests that $\mathrm{O}_{2}$ concentrations in the density plume indicated in Fig. 7 are the same as in the surface water.

The density plume indicated in Fig. 7 cannot be the result of pure river infiltration. This becomes clear from a simple 

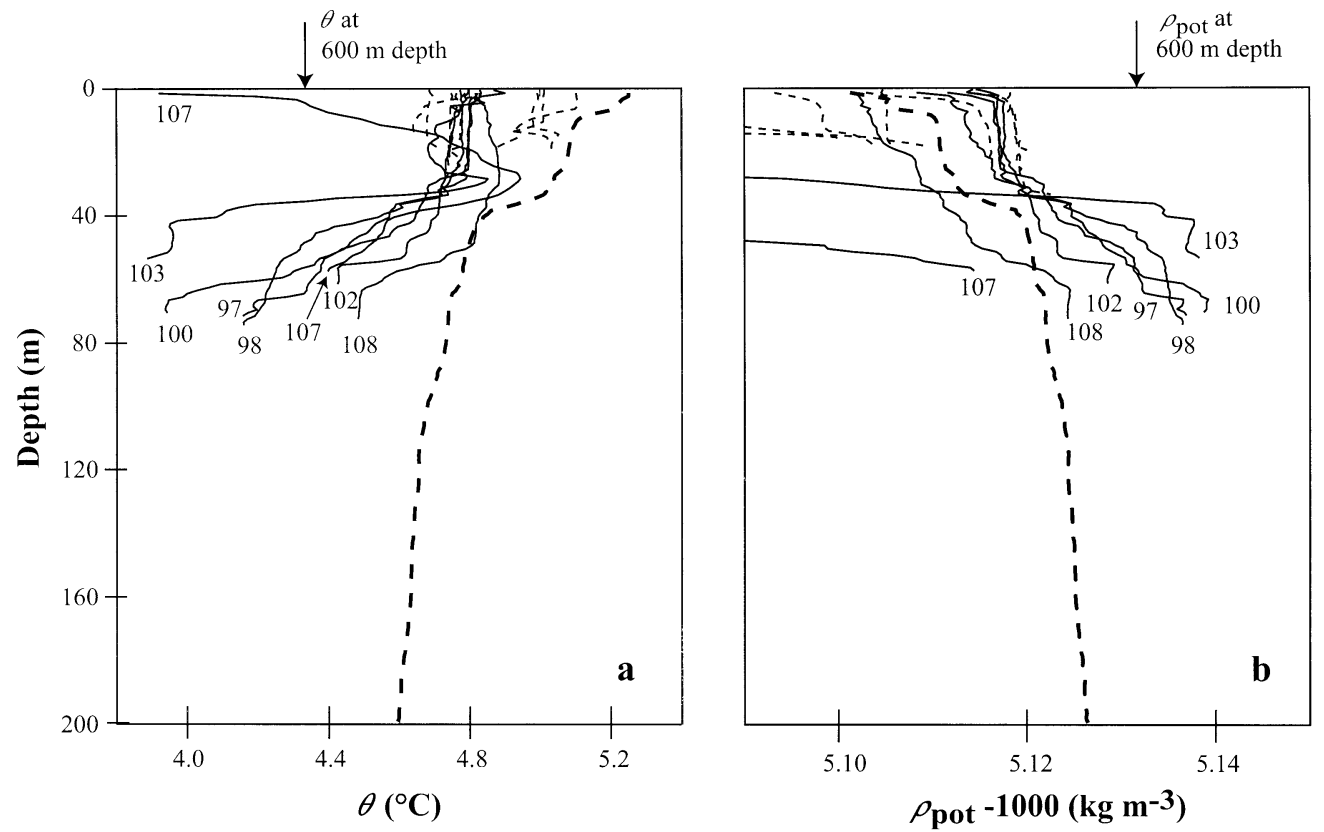

Fig. 6. Profiles of potential temperature $\theta$ (a) and potential density $\rho_{\text {pot }}$ (b) measured in March 2001 in the eastern shelf region. The coldest and densest water is found at the bottom of the submerged channels in the eastern shelf region. Solid lines characterize profiles measured in and over the channels, whereas dashed lines indicate profiles from shallower shelf stations. See Fig. 1c for station locations. The thick dashed lines characterize $\theta$ and $\rho_{\text {pot }}$ at the deepest station (Sta. 3a) for comparison. Arrows indicate minimum $\theta$ and maximum $\rho_{\text {pot }}$ in the deep water at Station 3a.

mixing calculation. The salinity in the density plume $S_{P}>$ 6.000 and the background salinity in the open lake $S_{L}<$ $6.006 \mathrm{~g} \mathrm{~kg}^{-1}$. Assuming the salinity of the river water $S_{R}<$ $0.25 \mathrm{~g} \mathrm{~kg}^{-1}$ (Tsigelnaya 1995), the fraction of river water in the density plume $x_{R}=\left(S_{L}-S_{P}\right) /\left(S_{L}-S_{R}\right)$ can only be $\sim 0.1 \%$. Because the ratio of river water to lake water in the plumes is very low, the river water has a negligible affect on the temperature of the plumes. If the river contributes only $0.1 \%$ to the mixture, then even if the river water were close to $0^{\circ} \mathrm{C}$ it would be able to cool lake water with a temperature of, say, $5^{\circ} \mathrm{C}$ by only $0.005^{\circ} \mathrm{C}$. Hence the low temperatures of the water at the bottom of the submerged channels cannot be generated by river inflow alone but must be predominantly the result of other processes yet to be identified.

Deep-water renewal by differential cooling: The mechanism driving the formation of cold density plumes in the channels is most likely differential cooling. During the winter season, heat loss from the lake surface leads to cooling of the surface waters. The associated increase in density must result in vigorous convection, because surface temperatures are typically $>2.6^{\circ} \mathrm{C}$, the temperature of maximum density. In the open water, the convective process leads to entrainment of water from deeper regions with temperatures always $>4.3^{\circ} \mathrm{C}$, resulting in a heat flux toward the surface and thus in an increase in surface temperature. In the shallow regions, the depth of convection is limited, and so is the reservoir of warm water available for entrainment. As a consequence, the water in the shallower regions becomes colder than the open water at the same depth. The resulting hori- zontal density gradients lead to an exchange between shallow and open water that reduces the temperature differences. However, the dense cold water in the shallower regions collects at the bottom of the channels. The walls of the channels restrict horizontal mixing to the direction along the channels and thus limit the entrainment of water from the shelf. Hence, the water at the bottom of the channels retains its characteristic properties, being less affected by horizontal mixing than either the shelf water or the open water.

Figure 8 summarizes our conceptual model of deep-water renewal in Lake Issyk-Kul. Differential cooling leads to the formation of cold, dense water in the shallow regions of the lake. This water collects at the bottom of the channels in the eastern shelf region and propagates along the channels toward the deep open-water region, where it sinks to a depth that corresponds to the density of the plume. The depth of the intrusions varies because (1) the density of the intruding water may vary with time and (2) the density profile of the ambient water may also vary with time, because $T$ and $S$ in the open water are both heterogeneous and horizontal advection is substantial.

In the shallow western part of the lake, intrusions similar to those in the eastern region were not observed. This, however, does not imply that deep-water formation by differential cooling is limited to the eastern region. On the one hand, only few profiles have been measured in the shallow western part. On the other hand, the channels provided by the sunken river valleys in the eastern shelf region not only preserve density gradients that enforce the propagation of density plumes but also preserve signals in $S, L T$, and $\mathrm{O}_{2}$ by which the density plumes can be identified. In the western part of 

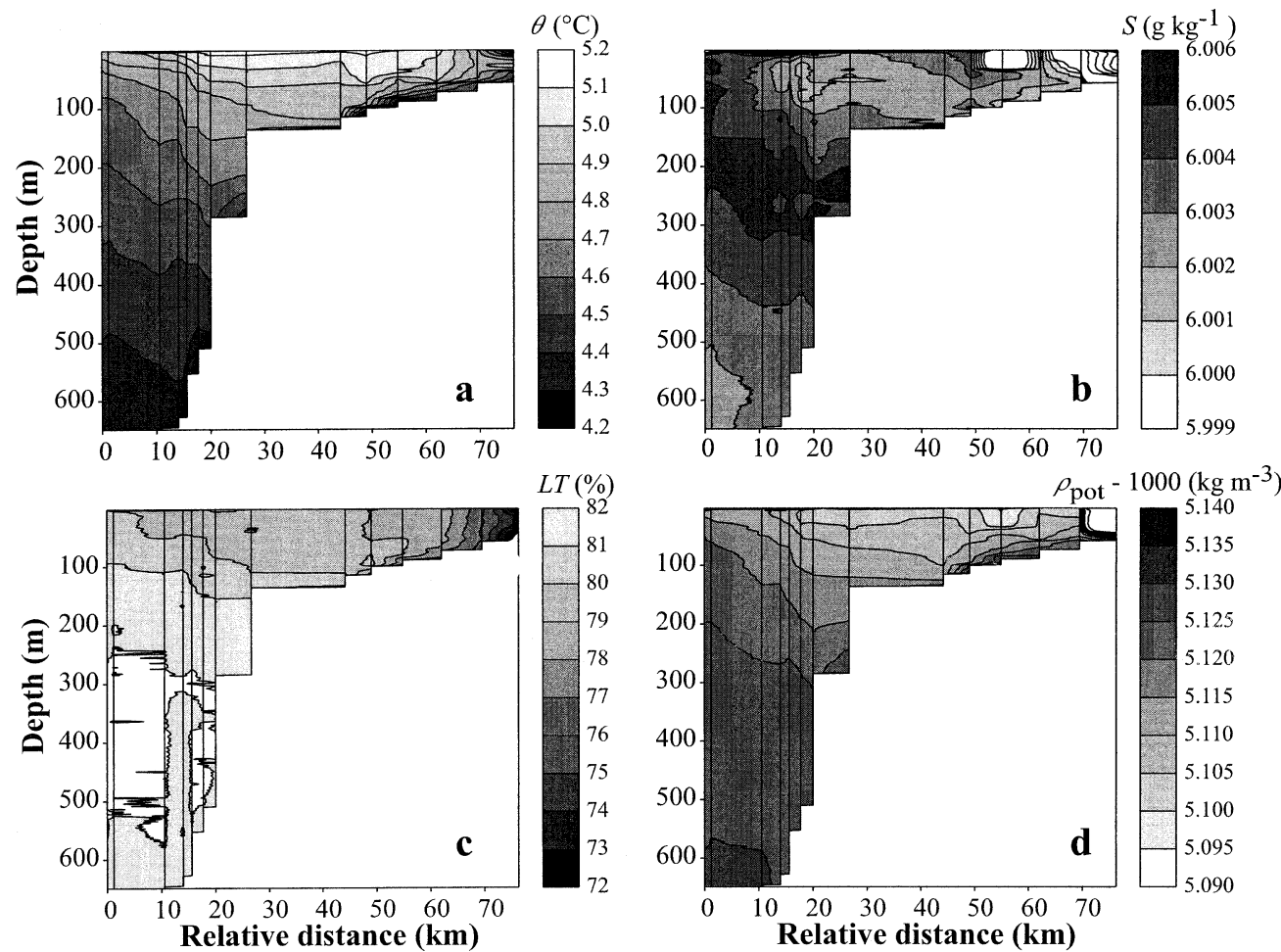

Fig. 7. Vertical distribution of potential temperature $(\theta)$, salinity $(S)$, light transmission $(L T)$, and potential density $\left(\rho_{\mathrm{pot}}\right)$ along the Karakol transect. This indicates a density plume characterized by low $\theta$, low $S$, and low $L T$ at the bottom of the main channel in the eastern shelf region. The locations of the profiles used in the contouring are indicated by thin vertical lines. See Fig. 1b,c for the locations of the stations of the Karakol transect (marked by solid circles connected with a solid line).
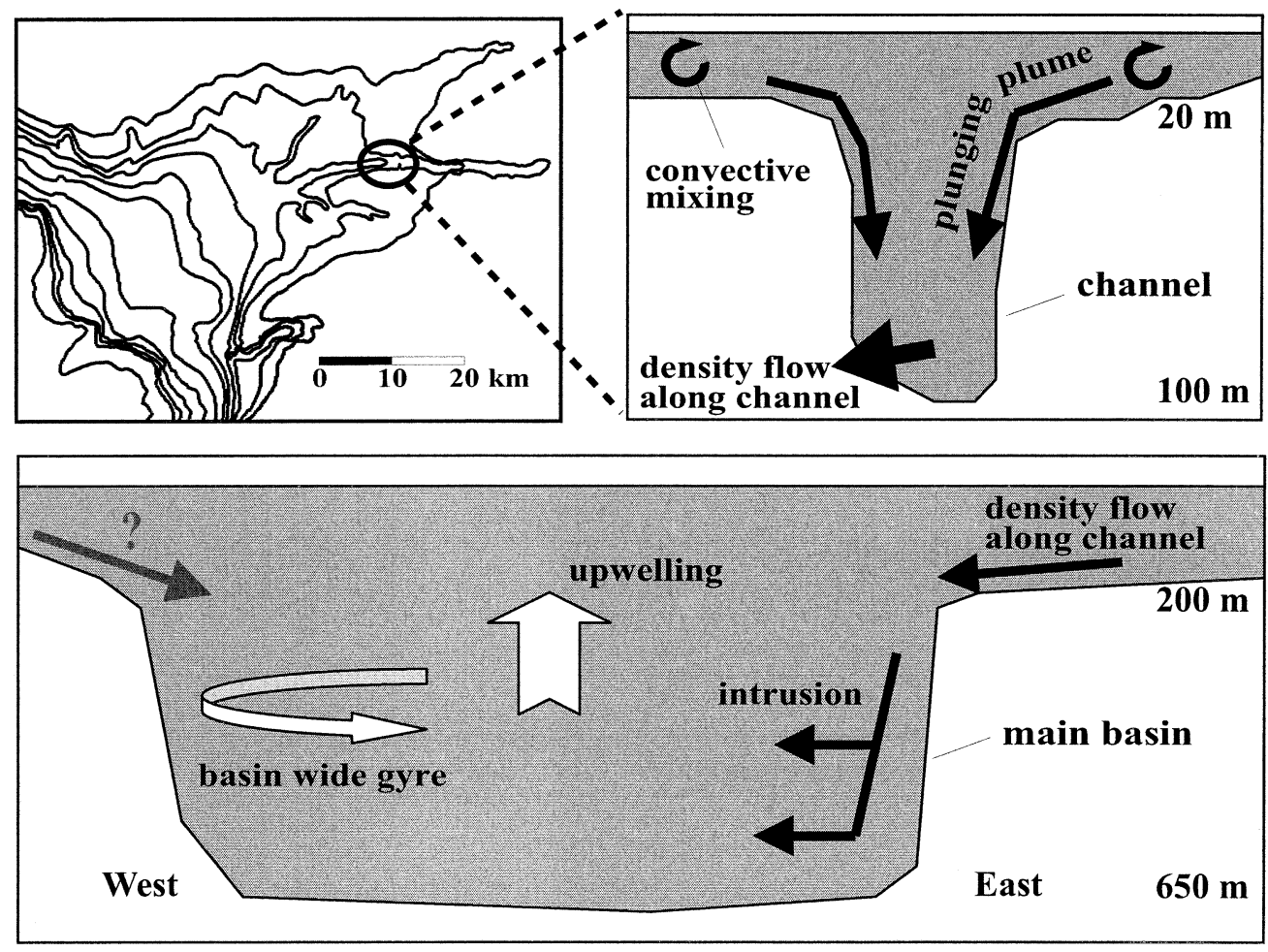

Fig. 8. Conceptual model of deep-water renewal in Lake Issyk-Kul by differential cooling. 

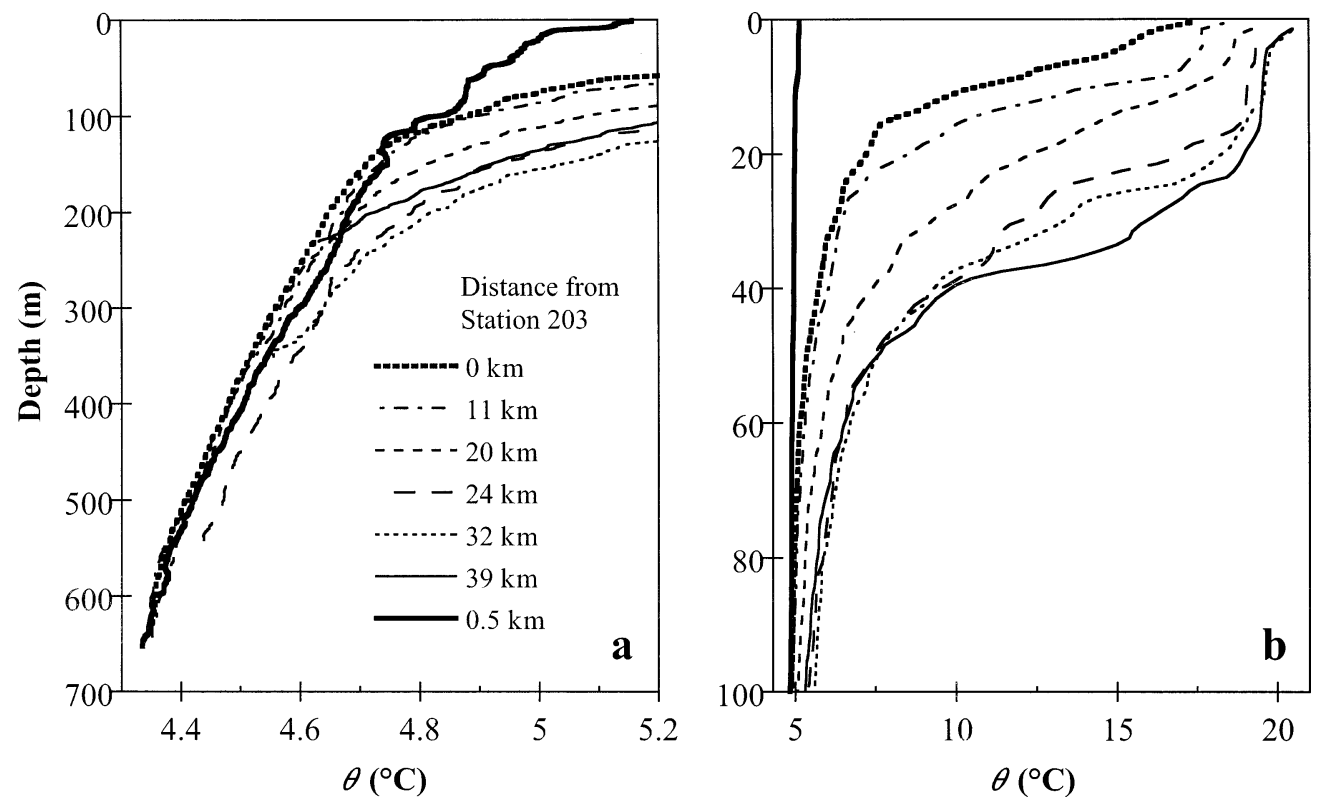

Fig. 9. Profiles of potential temperature $(\theta)$ measured in August at stations at different distances west of the central station (Sta. 203, labeled CS in Fig. 1). For comparison, the $\theta$ profile measured at the central station in March (Sta. 3a) is shown as a thick dashed line. (b) The top $100 \mathrm{~m}$ in more detail, demonstrating that the thermocline depth increases along the transect with increasing distance from the central station.

the lake, deep-water mixing by differential cooling may be active in a less focused way, so that it was not visible in our CTD profiles. In addition, in the western region values of $S$ and $L T$ in the surface water are very similar to those in the deep water. Hence, temperature-driven density plumes originating from the shallow western region should probably be characterized by peaks in dissolved oxygen only and could thus be distinguishable from density plumes originating in the eastern region of the lake.

In the southern part of the lake, intrusions were observed near channels leading into the deep water, and these may also be explained by differential cooling. However, in the southern region, the shoreline is steep and the shallow region comparatively small. Hence, the available data set is not sufficient to provide a clear identification of the origin of the intrusions in the southern region.

Data from the August field campaign-In the previous section on the March data, all tracers were interpreted together at specific locations in Lake Issyk-Kul. In the following section on the August data, the results for the tracers $\theta$, $S$, and $\mathrm{O}_{2}$ are presented and discussed in order.

Distribution of $\theta$ : Profiles of $\theta$ measured in August at stations along a transect from the central station toward the west are shown in Fig. 9a. Below $300 \mathrm{~m}$, the $\theta$ profile measured at the deepest station in August (Fig. 9a, thick dashed line) was similar to that measured in March (Fig. 9a, thick solid line). However, in August, a strong thermocline exists above $50 \mathrm{~m}$. In the open water far from the lake boundaries, the thermocline extends up to the lake surface, whereas, at stations closer to the shore, the thermocline is deeper and a warm mixed surface layer up to $20 \mathrm{~m}$ thick exists (Fig. 9b).
The horizontal distribution of $\theta$ along south-north and west-east transects (Fig. 10a,b) indicates that, in the top 200 $\mathrm{m}$, the boundary regions are significantly warmer than the central part of the lake. This confirms observations from earlier investigations (Romanovski and Shabunin 1981, 2002; Kipfer and Peeters 2002). The structure of the $\theta$ distribution has been explained by the effect of a basinwide gyre driven by a cyclonic wind field that causes upwelling in the center of the lake (Romanovski and Shabunin 1981, 2002). Such an upwelling would also explain why the surface mixed layer is thinner in the central part of the lake than in the shallower boundary regions. Kipfer and Peeters (2002) suggested that the horizontal temperature gradients near the surface could be additionally intensified by differential warming. At $60 \mathrm{~m}$ depth, the coldest water can be found in the center of the lake (Fig. 10c). Because this water is also the densest water (Fig. 10d), a large-scale dynamic process would be required to drive upwelling.

Distribution of $\mathrm{S}$ and $\mathrm{O}_{2}$ : Below $250 \mathrm{~m}$, the relative change of salinity with depth in August (Fig. 11b) was similar to that in March (Fig. 2b). A transect along the center line in the west-east direction shows a layer of comparatively saline water between 10 and $40 \mathrm{~m}$ depth (Fig. 11a). Near the surface, salinity was significantly reduced. The low salinities near the lake surface are possibly due to the effect of freshwater inflow from rivers, whereas evaporative processes may be the reason for the increased salinities at intermediate depths. Because the surface layer of low salinity extends over almost the entire transect, the larger salinities at intermediate depths are likely to be remnants from a few months before, when river inflow was significantly less, or may originate from evaporation in nearshore regions, espe- 

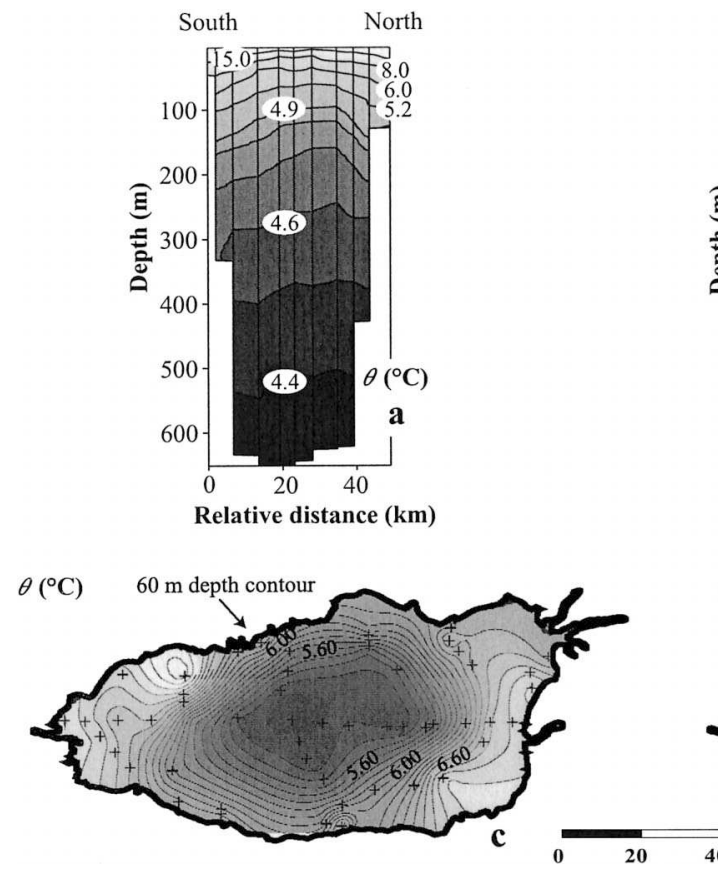
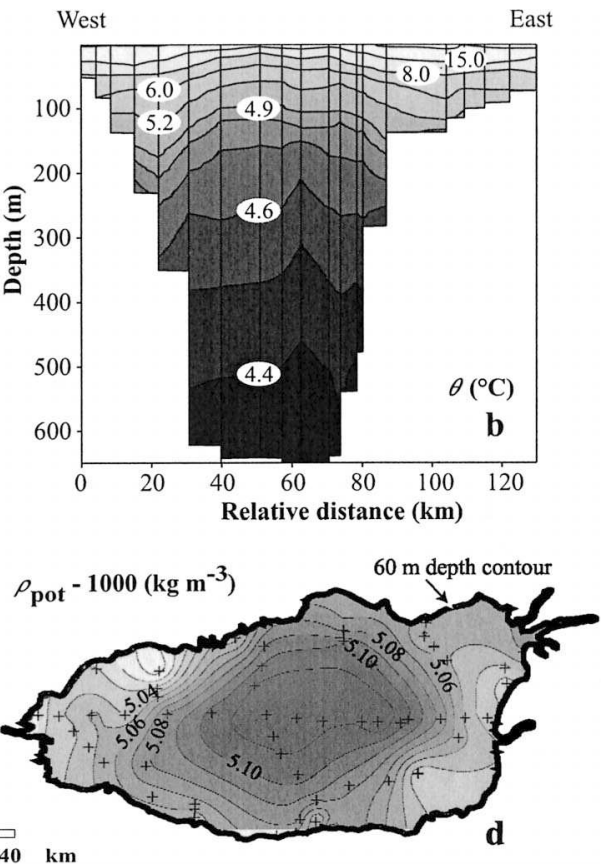

Fig. 10. Distribution of potential temperature $\theta$ in August along a south-north (a) and a westeast (b) transect through the deepest station. The horizontal distribution of $\theta$ at $60 \mathrm{~m}$ depth is shown in (c). The horizontal distribution of $\rho_{\text {pot }}$ at $60 \mathrm{~m}$ depth (d) is closely linked to that of $\theta$. Thin lines indicate the location of profiles used in the contouring of (a) and (b). The symbols (+) indicate the location of the measurements in (c) and (d).

cially in the west, from where the water could intrude as density plumes at 30-40 m depth. However, these are speculations that must be confirmed by additional measurements.

According to Winkler measurements on samples collected in the deep water, oxygen saturation levels in August are essentially the same as those in March. However, peak structures in the deep water similar to those observed in some of the $\mathrm{O}_{2}$ profiles measured with the oxygen sensor during the March expedition were not observed in any of the August $\mathrm{O}_{2}$ profiles. This suggests that intrusions do not occur during the summer months and that turbulent diffusive mixing must be sufficiently vigorous to erode the peak structures completely some time between March and August.

Mixing dynamics in August: In August, profiles from stations at the channels in the eastern shelf region showed no indication of anomalies similar to those observed during the March expedition. Signals in the different tracer profiles that would indicate intrusions into the deep water were not observed during the August expedition. The most prominent large-scale feature indicating vertical mixing processes was the doming structure in the distributions of potential temperature (Fig. 10a,c) and salinity (Fig. 11a), which, however, seemed to be limited to the top $200 \mathrm{~m}$.

Speculations on deep-water renewal by advective processes and the influence of environmental change-Transient tracer data indicated that the water at $600 \mathrm{~m}$ depth has a residence time $<10 \mathrm{yr}$, which suggests rapid deep-water renewal (Hofer et al. 2002; Vollmer et al. 2002a). New SF 6 data measured in samples collected at the deepest station
(Sta. 3) in August 2002 confirmed these earlier measurements (Table 2). The difference between the volume-weighted mean apparent $\mathrm{SF}_{6}$ age (Table 2) below and above 300 $\mathrm{m}$ depth suggests that the residence time below $300 \mathrm{~m}$ is $\sim 4$ yr. Using the ${ }^{3} \mathrm{H}-{ }^{3} \mathrm{He}$ ages of Hofer et al. (2002) instead of the $\mathrm{SF}_{6}$ ages gives a residence time of $\sim 5$ yr. Under the assumption that all water exchange occurs advectively, one obtains upper limits for the mean upwelling velocity in the open water at $300 \mathrm{~m}$ depth of $\sim 65 \mathrm{~m} \mathrm{yr}^{-1}$ and $\sim 50 \mathrm{~m} \mathrm{yr}^{-1}$, respectively. However, at present, it is not clear how much of the annual tracer transport to the deep water is due to advective processes and how much is due to vertical turbulent diffusion. The present study demonstrates that, during spring, convective mixing driven by differential cooling has a significant effect on tracer distributions in the deep water of Lake Issyk-Kul. However, quantification of the tracer transport to the deep water by advection during the cold seasons is difficult and would require additional data-not only spatially but also from other time periods during the cold seasons. In August 2001, advective processes apparently did not contribute to deep-water mixing, so vertical turbulent diffusion must be the dominant process for vertical transport within the deep water. $\mathrm{O}_{2}$ profiles from September 1996, however, had small but distinct peaks at $\sim 400, \sim 470$, and $\sim 520 \mathrm{~m}$ depth (Kipfer and Peeters 2002), which indicates that the effects of processes influencing the tracer distribution at great depths are visible even during the summer months. It is, however, not clear whether the peaks in the $\mathrm{O}_{2}$ profiles from 1996 indicate intrusions, because $\theta$ and $S$ showed no specific features at corresponding depths. The features in the $\mathrm{O}_{2}$ profile are most likely remnants of spring 


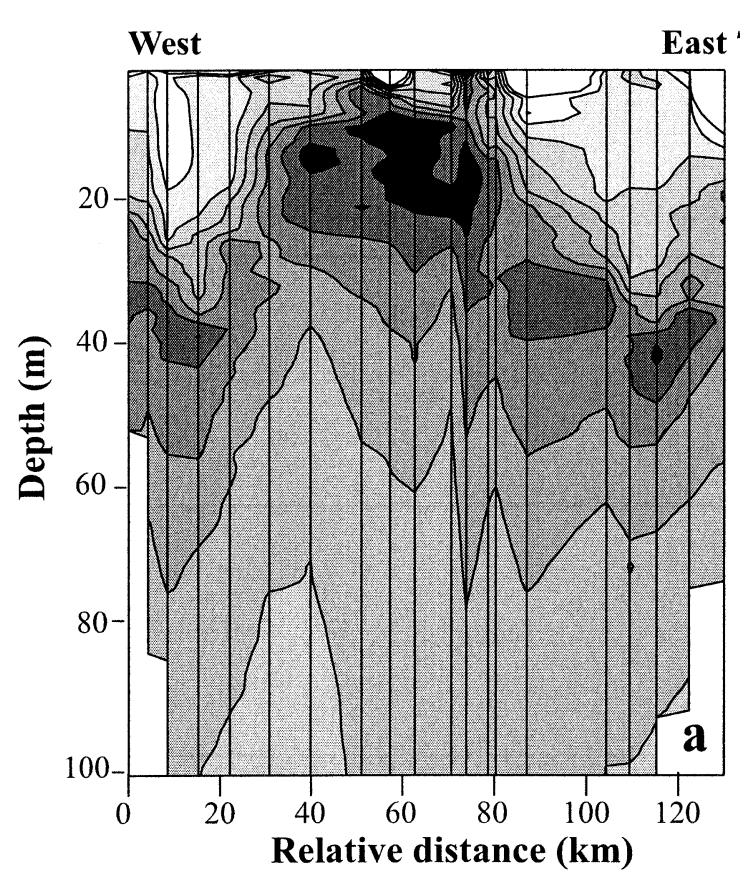

$S\left(\mathbf{g ~ k g}^{\mathbf{- 1}}\right)$

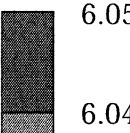

6.04

6.03

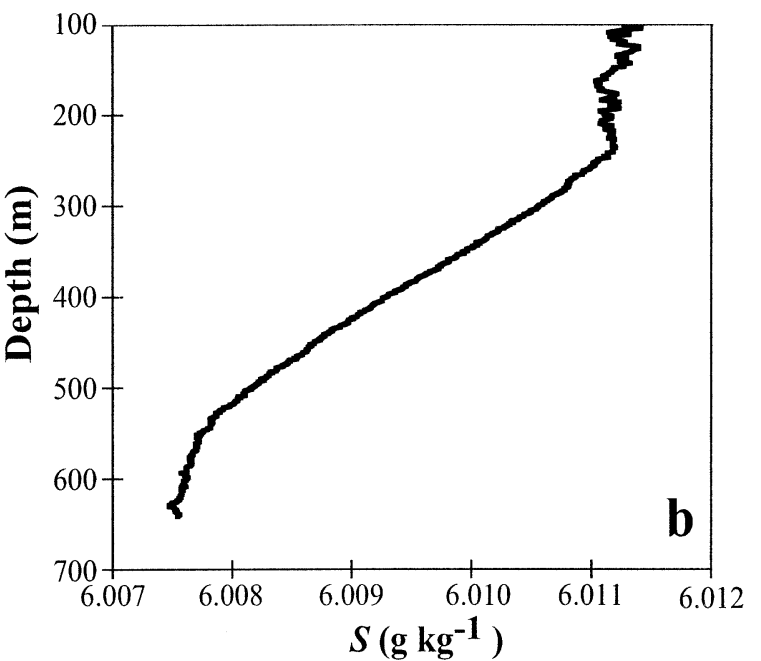

Fig. 11. Distribution of salinity $S$ in August. (a) Vertical distribution of $S$ in the top $100 \mathrm{~m}$ along a west-east transect along the central line through the deepest station, indicating a water mass of high salinity at $\sim 30-40 \mathrm{~m}$ depth overlain by water with comparatively low salinity. Thin lines indicate the location of profiles used in the contouring. (b) Profile of $S$ below $100 \mathrm{~m}$ depth at the deepest station.

mixing and not the result of processes active during the summer.

The deep-water temperatures above $4.33^{\circ} \mathrm{C}$ measured in 2001 are the highest deep-water temperatures ever observed in Lake Issyk-Kul. Between 1981 and 1988, the deep-water temperatures ranged between $3.7^{\circ} \mathrm{C}$ and $4.1^{\circ} \mathrm{C}$ (Romanovski 1991 ), in 1996 they were $\sim 4.16^{\circ} \mathrm{C}$ (Kipfer and Peeters 2002 ), and in 2000 they were $\sim 4.29^{\circ} \mathrm{C}$ (Vollmer et al. $2002 b$ ). Kipfer and Peeters (2002) suggested that the increased deep-water temperature measured in 2001 may have
Table 2. Profile of $\mathrm{SF}_{6}$ concentrations measured in water samples collected at the deepest station on 4 August 2001. SF $_{6}$ ages were calculated using the procedure outlined by Hofer et al. (2002) and are based on the atmospheric concentrations of Maiss and Brenninkmeijer (1998) and on the solubilities of Bullister et al. (2002) using $S=6 \mathrm{~g} \mathrm{~kg}^{-1}$ and $p=0.813 \mathrm{~atm}$.

\begin{tabular}{cccc}
\hline \hline $\begin{array}{c}\text { Depth } \\
(\mathrm{m})\end{array}$ & $\begin{array}{c}\mathrm{SF}_{6} \\
\left(\mathrm{pg} \mathrm{kg}^{-1}\right)\end{array}$ & $\begin{array}{c}\text { Temperature } \\
\left({ }^{\circ} \mathrm{C}\right)\end{array}$ & $\begin{array}{c}\mathrm{SF}_{6} \text { age } \\
(\mathrm{yr})\end{array}$ \\
\hline 10 & 0.283 & 10 & - \\
10 & 0.403 & 10 & - \\
50 & 0.265 & 5.3 & 0.9 \\
50 & 0.231 & 5.3 & 3.1 \\
100 & 0.232 & 4.9 & 3.4 \\
100 & 0.215 & 4.9 & 4.5 \\
150 & 0.210 & 4.7 & 5.0 \\
150 & 0.227 & 4.7 & 3.8 \\
200 & 0.180 & 4.6 & 7.3 \\
200 & 0.205 & 4.6 & 5.4 \\
250 & 0.220 & 4.6 & 4.4 \\
250 & 0.180 & 4.6 & 7.3 \\
300 & 0.167 & 4.6 & 8.3 \\
300 & 0.193 & 4.6 & 6.3 \\
350 & 0.177 & 4.5 & 7.6 \\
350 & 0.180 & 4.5 & 7.3 \\
400 & 0.190 & 4.5 & 6.6 \\
400 & 0.168 & 4.5 & 8.3 \\
450 & 0.185 & 4.5 & 7.0 \\
450 & 0.166 & 4.5 & 8.4 \\
500 & 0.150 & 4.4 & 9.8 \\
500 & 0.154 & 4.4 & 9.5 \\
550 & 0.176 & 4.4 & 7.7 \\
550 & 0.154 & 4.4 & 9.5 \\
600 & 0.162 & 4.4 & 8.8 \\
600 & 0.174 & 4.4 & 10.2 \\
650 & 0.131 & 4.3 & \\
650 & 0.146 & 4.4 & \\
\hline & & & -5 \\
\hline
\end{tabular}

been the result of global warming, as has been observed, for instance, in Lake Zurich, Switzerland over the past $50 \mathrm{yr}$ (Livingstone 2003). The long-term increase of the February surface temperatures in Lake Issyk-Kul has also been attributed to global warming (Romanovski and Shabunin 2002). In any case, because, in Lake Issyk-Kul, temperature and density stratification are closely linked, mixing conditions and the relative importance of advective versus diffusive mixing in the past were possibly not the same as they are today. Taking a long-term paleolimnological view, lake level fluctuations and the associated change in the salinity, and hence density, of the lake water may also be important for the processes driving advective deep-water renewal. In the past $90 \mathrm{yr}$, the lake level has dropped continuously by $\sim 3$ m (Tsigelnaya 1995; Romanovski 2002), which implies a corresponding increase in the salinity and density of the near-surface water that could have resulted in enhanced advective deep-water exchange. During periods of increasing lake level, surface water salinity and density decrease, thus presumably reducing advection to the deep water. Such a mechanism has been suggested to be responsible for the large residence times of the deep water of the Caspian Sea ( $\sim 20 \mathrm{yr}$; Peeters et al. 2000). Because the level of Lake Issyk-Kul was significantly lower in the 15 th century than 
in the early 19th century (Tsigelnaya 1995), rising water levels might have resulted in deep-water anoxia; if so, the geochemical analysis of sediment cores would bring this to light.

\section{References}

Bullister, J. L., D. P. Wisegarver, And F. A. Menzia. 2002. The solubility of sulfur hexafluoride in water and seawater. DeepSea Res. I 49: 175-187.

Crawford, G. B., AND R. W. Collier. 1997. Observations of a deep-mixing event in Crater Lake, Oregon. Limnol. Oceanogr. 42: 299-306.

Culkin, F., AND N. D. SMITH. 1980. Determination of the concentration of potassium chloride solution having the same electrical conductivity, at $15^{\circ} \mathrm{C}$ and infinite frequency, as standard sea water of salinity 35.0000 (chlorinity 19.37394). IEEE J. Ocean. Engineer. OE-5(1): 22-23.

FInGER, D. 2002. Tiefenwasserbildung im Gebirgssee Issyk-Kul (in German). Diploma thesis, EAWAG/ETH-Zürich.

Fofonoff, N. P., AND R. C. Millard JR. 1983. Algorithms for computation of fundamental properties of seawater. UNESCO Tech. Papers Mar. Sci., 44. UNESCO.

Hofer, M., AND OTHERS. 2002. Rapid deep-water renewal in Lake Issyk-Kul (Kyrgyzstan) indicated by transient tracers. Limnol. Oceanogr. 47: 1210-1216.

Hohmann, R. 1997. Deep-water renewal in Lake Baikal. Dissertation, ETH 12029, ETH Zürich.

, R. Kipfer, F. Peeters, G. Piepke, D. M. Imboden, and M. N. Shimaraev. 1997. Processes of deep-water renewal in Lake Baikal. Limnol. Oceanogr. 42: 841-855.

KIPFER, R., AND OTHERS. 2000. New evidence for deep water exchange in Lake Tanganyika. EOS Trans. Am. Geophys. Union 80: OS239.

- AND F. PeETERs. 2002. Using transient conservative and environmental tracers to study water exchange in Lake IssykKul, p. 89-100. In J. Klerkx and B. Imanackunov, [eds.], Lake Issyk-Kul: Its natural environment. NATO science series IV. Earth and environmental sciences vol 13. NATO.

LiVInGSTONE, D. M. 2003. Impact of secular climate change on the thermal structure of a large temperate central European lake. Clim. Change. 57: 205-225.

Maiss, M., And C. A. M. BrenninkmeiJer. 1998. Atmospheric SF6: Trends, sources, and prospects. Environ. Sci. Technol. 32: 3077-3086.

Malm, J., D. Mironov, A. TerzheviK, And L. Jönsson. 1994. Investigation of the spring thermal regime in Lake Ladoga using field and satellite data. Limnol. Oceanogr. 39: 1333-1348.

McManus, J., R. W. Collier, C.-T. A. Chen, And J. Dymond. 1992. Physical properties of Crater Lake, Oregon: A method for the determination of a conductivity- and temperature-dependent expression for salinity. Limnol. Oceanogr. 37: 41-53.
PeEters, F., AND OTHERs. 2000. Analysis of deep-water exchange in the Caspian Sea based on environmental tracers. Deep-Sea Res. I 47: 621-654.

- G. Piepke, R. Kipfer, R. Hohmann, And D. M. Imboden. 1996. Description of stability and neutrally buoyant transport in freshwater lakes. Limnol. Oceanogr. 41: 1711-1724.

Rodgers, G. K. 1965. The thermal bar in the Laurentian Great Lakes. 8th Conference on Great Lakes Research, Milwaukee, WI. Univ. of Michigan Press.

Romanov, V., L. S. Vlasova, A. V. Meskheteli, and L. V. SalNOVA. 1989. A tritium study of the formation of natural waters of Issyk-Kul basin (in Russian). Vodnye Resursy 4: 82-94.

RomAnovsKi, V. V. 1991. Lake Issyk-Kul as a natural system (in Russian). Ilim Publishing House.

. 2002. Water level fluctuations and water balance of Lake Issyk-Kul, p. 45-57. In J. Klerkx and B. Imanackunov, [eds.], Lake Issyk-Kul: Its natural environment. NATO science series IV. Earth and environmental sciences vol 13. NATO.

, AND G. SHABUNIN. 1981. Upwelling in Lake Issyk-Kul, p. 160-169 (in Russian). In Dynamics of modern coastal processes in Lake Issyk-Kul. Ilim Publishing House.

— AND —. 2002. Currents and vertical water exchange in Lake Issyk-Kul, p. 77-88. In J. Klerkx and B. Imanackunov [eds.], Lake Issyk-Kul: Its natural environment. NATO science series IV. Earth and environmental sciences vol 13. NATO.

Shimaraev, M. N., N. G. Granin, AND A. A. Zhadanov. 1993. Deep ventilation of Lake Baikal due to spring thermal bars. Limnol. Oceanogr. 38: 1068-1072.

TsigelnAYA, I. D. 1995. Issyk-Kul Lake, p. 199-229. In A. F. Maudych [ed.], Enclosed seas and large lakes of Eastern Europe and Middle Asia. SPB.

UNESCO, ICES, SCOR, AND IAPSO. 1981. Background papers and supporting data on the international equation of state of seawater 1980. UNESCO technical papers in marine science 38. UNESCO.

Vollmer, M. K., R. F. Weiss, P. Schlosser, and R. T. Williams. 2002a. Deep-water renewal in Lake Issyk-Kul. Geophys. Res. Lett. 29: 1-4.

一, - R. T. Williams, K. K. Falkner, X. QiU, E. A. RALPH, AND V. V. RomANOVSKy. 2002b. Physical and chemical properties of the waters of saline lakes and their importance for deep-water renewal: Lake Issyk-Kul, Kyrgyzstan. Geochim. Cosmochim. Acta 66: 4235-4246.

WALKER, S. J., AND R. G. WATTS. 1995. A three-dimensional numerical model of deep ventilation in temperate lakes. J. Geophys. Res. 100: 22711-22731.

Weiss, R. F., E. C. Carmack, and V. M. Koropalov. 1991. Deepwater renewal and biological production in Lake Baikal. Nature 349: 665-669.

Received: 16 July 2002

Accepted: 31 December 2002

Amended: 3 February 2003 